\title{
Modelling and Simulation on a New Double-Layer Diffluent Combustion System
}

\author{
K.P. Qi \\ School of Traffic and Transport Engineering \\ Dalian JiaoTong University \\ China
}

\author{
W.Q. Long \\ Institute of Internal Combustion Engine \\ Dalian University of Technology \\ China
}

\begin{abstract}
In order to investigate the influence of combustion chamber geometry on the formation of air-fuel mixture in diesel engine, a new double-layer diffluent combustion system for DI diesel engine was proposed which had a collision platform with circular oriented-surface. The mixing process of the fuel spray and air in this combustion chamber is modelled and numerical simulation is executed by the software AVL FIRE. The simulation results indicate that the fuel spray distribution becomes more uniformed for the double-layer diffluent combustion system than that of the $\omega$ combustion system. It can be concluded that the combustion chamber geometry put important effect on the formation of air-fuel mixture in combustion chamber.
\end{abstract}

Keywords-diesel engine; double-layer diffluent combustion system; combustion chamber geometry; numerical simulation

\section{INTRODUCTION}

As we know, the combustion process and emission properties of DI diesel engine are mainly determined by the uniformity and distribution of air-fuel mixture in combustion chamber. The utilization of spray impingement mechanism is used to enlarge the spray distribution and improve the space atomization of fuel spray. Therefore, the relationship between the fuel spray and the combustion chamber geometry is the key factor which influences the formation of air-fuel mixture in combustion chamber [1-3]. Currently, many researchers have paid their efforts to match the fuel spray and the combustion chamber geometry in combustion chamber of diesel engines [4-8]. The research results put their emphases on the relationship between combustion chamber geometry and the formation of air-fuel mixture in combustion chamber.

\section{STRUCTURE OF DOUBLE-LAYER DIFFLUENT COMBUSTION SYSTEM}

On the basis of the principle of spray impingement orientation and fuel atomization distribution, a new doublelayer diffluent combustion system for DI diesel engine is proposed which has a collision platform with circular oriented-surface in this research. Figure 1 shows the geometry diagram of double-layer diffluent combustion system. In this combustion system, the combustion chamber is divided into lower and upper layers by the collision platform. The fuel injected from multi-hole injector is divided into two parts due to the effect of collision platform, and the two parts of fuel spray diffluent to the upper and lower layers of the combustion chamber along the circular oriented-surface. Further, the fuel spray can increase its dispersing velocity and enlarge the spatial distribution of airfuel mixture. Moreover, much quantities of air are entrained into the air-fuel mixture during the atomization process of fuel spray. As a result, the air-fuel mixture becomes more sufficient, because secondary atomization of fuel spray is better realized through the matching between the fuel spray and the combustion chamber geometry.

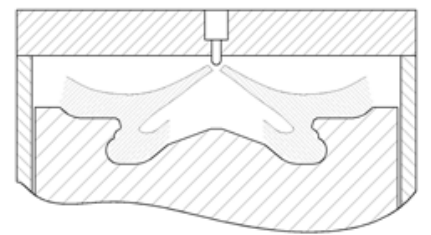

FIGURE I.THE GEOMETRY DIAGRAM OF DOUBLE-LAYER DIFFLUENT COMBUSTION SYSTEM.

\section{MODELLING OF MIXING PROCESS OF THE FUEL SPRAY AND AIR}

The model of mixing process of the fuel spray and air is composed of the basic equations, the discrete droplet model, the turbulence model, the spray impingement model, the spray breakup model and the spray evaporation model.

\section{A. Basic Equations}

The basic equations are based on the turbulent governing equation and homogeneous flow equation which include momentum conservation equation, mass conservation equation and energy conservation equation.

\section{1) Momentum conservation equation}

Momentum conservation equation is given by eqn. (1), (2) and (3) [9]:

$$
\begin{gathered}
\frac{\partial\left(\rho u_{j}\right)}{\partial t}+\frac{\partial}{\partial x_{j}}\left(\rho u_{j} u_{i}-\tau_{i j}\right)=-\frac{\partial p}{\partial x_{i}}+S_{i} \\
\tau_{i j}=2 \mu S_{i j}-\frac{2}{3} \mu \frac{\partial u_{k}}{\partial x_{k}} \delta_{i j}-\overline{\rho u_{j}^{\prime} u_{i}^{i}} \quad(i, j, k=1,2,3) \\
S_{i j}=\frac{1}{2}\left(\frac{\partial u_{i}}{\partial x_{j}}+\frac{\partial u_{j}}{\partial x_{i}}\right)
\end{gathered}
$$


2) Mass conservation equation

Mass conservation equation is calculated by eqn. (4) and (5) [9]:

$$
\begin{gathered}
\frac{\partial \rho}{\partial t}+\frac{\partial}{\partial x_{j}}\left(\rho u_{j}\right)=S_{m} \\
\frac{\partial}{\partial x_{j}}\left(\rho u_{j}\right)=\frac{\partial}{\partial x_{1}}\left(\rho u_{1}\right)+\frac{\partial}{\partial x_{2}}\left(\rho u_{2}\right)+\frac{\partial}{\partial x_{3}}\left(\rho u_{3}\right)
\end{gathered}
$$

\section{3) Energy conservation equation}

Energy conservation equation is expressed by eqn. (6) [9]

$$
\frac{\partial(\rho h)}{\partial t}+\frac{\partial}{\partial x_{j}}\left(\rho u_{j} h+\overline{\rho u_{j}^{\prime} h^{\prime}}\right)=\frac{\partial p}{\partial t}+u_{j} \frac{\partial p}{\partial x_{j}}+\tau_{i j} \frac{\partial u_{i}}{\partial x_{j}}+S_{h}
$$

\section{B. Discrete Droplet Model}

The discrete droplet model is mainly described the trace and the speed of droplet as follows [13]:

$$
\begin{gathered}
m_{d}=\frac{d u_{i d}}{d t}=F_{i d r}+F_{i g}+F_{i p}+F_{i b} \\
F_{i d r}=D_{p} \cdot U_{i r e l} \\
F_{i g}=V_{p}\left(\rho_{p}-\rho_{g}\right) g_{i} \\
F_{i p}=V_{P} \nabla P
\end{gathered}
$$

\section{Turbulence Model}

The turbulent model is also needed to be established which make sure that the governing equation is closed. The gas flow in diesel engine is a kind of high Reynolds number flow, so the high Reynolds number double k- $\varepsilon$ equation model are applied in this research [10-11]:

$$
\begin{gathered}
\frac{\partial}{\partial t}(\rho k)+\frac{\partial}{\partial x_{j}}\left(\rho U_{j}{ }^{k}\right)=\rho P-\rho \varepsilon+\frac{\partial}{\partial x_{j}}\left[\left(\mu+\frac{\mu_{t}}{\sigma_{k}}\right) \frac{\partial k}{\partial x_{j}}\right] \\
\frac{\partial}{\partial t}(\rho \varepsilon)+\frac{\partial}{\partial x_{j}}\left(\rho U_{j}{ }^{\varepsilon}\right)=C_{s 1} f_{1} \frac{\rho P_{\varepsilon}}{k}-C_{s 2} f_{2} \frac{\rho \varepsilon^{2}}{k}+\frac{\partial}{\partial x_{j}}\left[\left(\mu+\frac{\mu_{t}}{\sigma_{\varepsilon}}\right) \frac{\partial \varepsilon}{\partial x_{j}}\right]
\end{gathered}
$$

\section{Spray Impingement Model}

The Particle-Wall impingement model is selected as the spray impingement model in this study which is raised by Reitz and Naber. In this model, there are two different reflex processes for different value of Weber. When the value of Weber is larger, liquid jet reflex process would be selected. Otherwise, rebound reflex process would be chosen if the value of Weber is smaller [12]. The Weber is defined as the following equation:

$$
W_{e}=\frac{\rho_{d} D_{d} U_{n, i n}^{2}}{\sigma}
$$

\section{E. Spray Breakup Model}

The spray breakup model is defined by WAVE and there are two different models in this model which is called highspeed break-up model and low-speed break-up model. The break-up rate of oil droplets are given by equations as follows [13]:

$$
\begin{aligned}
\frac{d r}{d t} & =\frac{-\left(r-r_{\text {stable }}\right)}{\tau} \\
\tau & =\frac{3.726 C_{2} r}{A \Omega}
\end{aligned}
$$

\section{F. Spray Evaporation Model}

There are four hypotheses is set when the spray evaporation model is developed. First, all of oil droplets are spherical symmetry. Second, a quasi-stable gas film stays around oil droplets. Third, the temperature of oil droplets along the diameter is the same. Fourth, fluid around oil droplets has the same physical property. Based on these hypotheses, the change rate of oil droplets' temperature is given by Dukowicz [14]:

$$
m_{d} c_{p d} \frac{d T_{d}}{d t}=L \frac{d m_{d}}{d t}+\dot{Q}
$$

\section{SIMULATION RESULTS AND DISCUSSIONS}

According to the working process and property parameters of 135 single-cylinder diesel engine, the simulation model is executed for the purpose of investigate the formation of air-fuel mixture for the new double-layer diffluent combustion system. The initial parameters of boundary conditions for the simulation model are listed in Table 1.

The comparisons of calculated results and experimental data of in-cylinder pressure and heat release rate at rated speed and rated load of diesel engine operating condition for the new double-layer diffluent combustion system are shown in Figure 2. It can be seen from Figure 2 (a) and Figure 2 (b) that the two curves of calculated results and experimental data of in-cylinder pressure and heat release rate have well agreements. These results indicate that the model developed in this research is reasonable which means that the model is validated to be applied to predict the mixture formation for DI diesel engine.

TABLE I. THE INITIAL PARAMETERS OF BOUNDARY CONDITIONS FOR THE SIMULATION MODEL.

\begin{tabular}{|l|l|l|l|}
\hline Speed & $1500\left(\mathrm{r} \bullet \mathrm{min}^{-1}\right)$ & $\begin{array}{l}\text { Intake swirl } \\
\text { ratio }\end{array}$ & 1.2 \\
\hline Power & $14.7(\mathrm{~kW})$ & $\begin{array}{l}\text { Initial } \\
\text { Temperature }\end{array}$ & $303(\mathrm{~K})$ \\
\hline Injector type & $8 \times 0.16 \times 150^{\circ}$ & $\begin{array}{l}\text { Temperature of } \\
\text { piston }\end{array}$ & $525(\mathrm{~K})$ \\
\hline $\begin{array}{l}\text { Injection } \\
\text { pressure }\end{array}$ & $110(\mathrm{MPa})$ & $\begin{array}{l}\text { Temperature of } \\
\text { cylinder head }\end{array}$ & $425(\mathrm{~K})$ \\
\hline $\begin{array}{l}\text { Advanced } \\
\text { fuel injection } \\
\text { angle }\end{array}$ & $9\left({ }^{\circ} \mathrm{CABTDC}\right)$ & $\begin{array}{l}\text { Temperature of } \\
\text { cylinder liner }\end{array}$ & $375(\mathrm{~K})$ \\
\hline
\end{tabular}



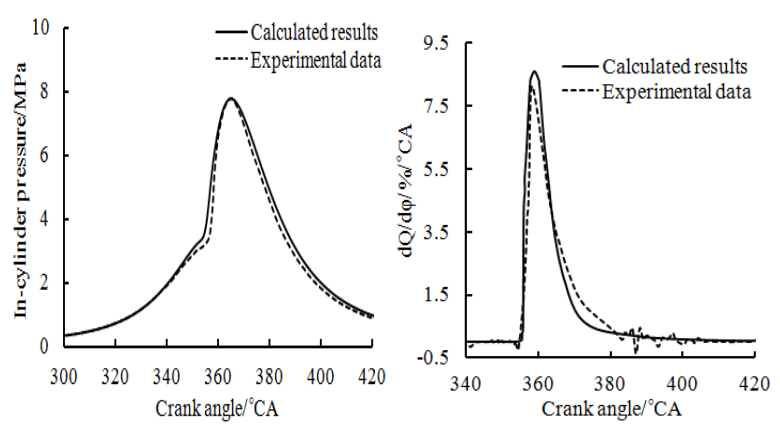

(A)IN-CYLINDER PRESSURE

(B) $\mathrm{DQ} / \mathrm{D} \Phi$

FIGURE II. COMPARISONS OF CALCULATED RESULTS AND EXPERIMENTAL DATA OF IN-CYLINDER PRESSURE AND HEAT RELEASE RATE AT RATED OPERATING CONDITION.

Figure 3 shows the comparisons of the equivalence ratio distribution of air-fuel mixture between the $\omega$ combustion system and the double-layer diffluent combustion system. From Figure 3, it is observed that the fuel spray has not reached the combustion chamber wall surface for the $\omega$ combustion system, while the front part of fuel spray has impinged the collision platform and the double-layer diffluence has been realized by the utilization of the orientedsurface for the double-layer diffluent combustion system at $5^{\circ} \mathrm{CA}$ BTDC. Further, the fuel spray has reached the combustion chamber wall surface and the zone of high concentration of air-fuel mixture has been formed at the accumulated point for the $\omega$ combustion system when the crank angle changes from TDC to $5^{\circ} \mathrm{CA}$ ATDC. During the same operating period of crank angle, the fuel spray has been divided into two parts by the aid of the circular orientedsurface and the smaller equivalence ratio of air-fuel mixture has been formed in the combustion chamber for the doublelayer diffluent combustion system. Moreover, the zone of high concentration of air-fuel mixture has moved to the bottom of combustion chamber along its wall surface, and the other part of air-fuel mixture has moved to the cylinder wall by the dint of squish flow for the $\omega$ combustion system, when the crank angle shifts from $5^{\circ} \mathrm{CA}$ ATDC to $15^{\circ} \mathrm{CA}$ ATDC. On the other hand, the air-fuel mixture at the bottom of combustion chamber has moved along the clockwise direction of collision platform and the smaller equivalence ratio of air-fuel mixture has been formed in the upper layer for the double-layer diffluent combustion system when the crank angle shifts from $5^{\circ} \mathrm{CA}$ ATDC to $15^{\circ} \mathrm{CA}$ ATDC. At last, it can seen from Figure 3 that the equivalence ratio of air-fuel mixture is 2.3 at the $\omega$ combustion chamber wall surface and the equivalence ratio of air-fuel mixture is 1.8 at the upper plane of its piston, when the crank angle arrives to $20^{\circ} \mathrm{CA}$ ATDC. At the same time, the equivalence ratio of airfuel mixture is 1.5 at lower layer and 0.6 at upper layer in combustion chamber respectively when the crank angle arrives to $20^{\circ} \mathrm{CA}$ ATDC for the double-layer diffluent combustion system. The simulation results demonstrate that the equivalence ratio distribution of air-fuel mixture for the double-layer diffluent combustion system is better uniformed than that of the $\omega$ combustion system.

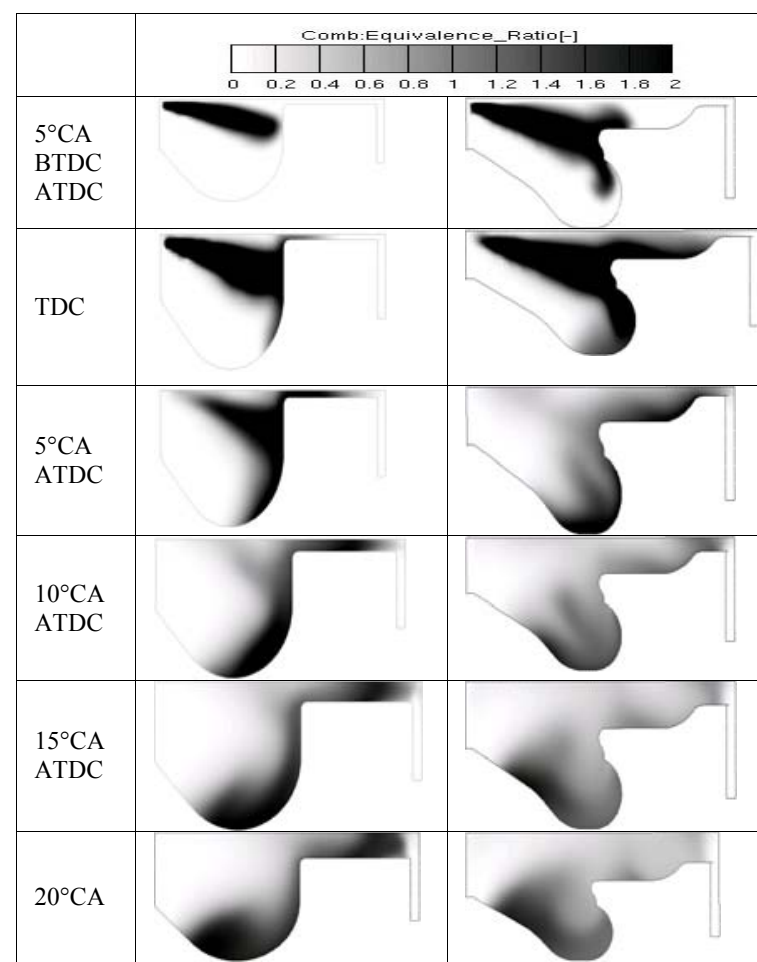

FIGURE III. COMPARISONS OF THE EQUIVALENCE RATIO DISTRIBUTION OF AIR-FUEL MIXTURE BETWEEN THE $\Omega$ COMBUSTION SYSTEM AND THE DOUBLE-LAYER DIFFLUENT COMBUSTION SYSTEM.

\section{CONCLUSIONS}

In this paper, a new double-layer diffluent combustion system is proposed which has a collision platform with circular oriented-surface in order to improve the characteristics of air-fuel mixture for DI diesel engine. In this double-layer diffluent combustion system, the double-layer diffluence and secondary atomization can be realized by the aid of favourable match between the fuel spray and the combustion chamber geometry. The simulation results demonstrate that the fuel spray is better atomized from the comparisons of the equivalence ratio distribution of air-fuel mixture for the double-layer diffluent combustion system than that of the $\omega$ combustion system. Therefore, the proper structure of the double-layer diffluent combustion system puts important effect on the distribution of air-fuel mixture of DI diesel engine.

\section{REFERENCES}

[1] Jaichandar S., Annamalai K.. Influences of re-entrant combustion chamber geometry on the performance of Pongamia biodiesel in a DI diesel engine. Energy, 44(1), pp. 633-640,2012.

[2] Jaichandar S., Kuma P. S., Annamalai K. Combined effect of injection timing and combustion chamber geometry on the performance of a biodiesel fueled diesel engine. Energy, 47(1), pp. 388-394,2012.

[3] Takashi K. Kusaka J. Improvement of Combustion and Exhaust Gas Emissions in a Passenger Car Diesel Engine by Modification of Combustion Chamber Design. SAE Paper 2006-01-3435,2006.

[4] S.W. Park. Optimization of combustion chamber geometry for stoichiometric diesel combustion using a micro genetic algorithm. Fuel Processing Technology, 91(11), pp. 1742-1752,2010. 
[5] Adrian C.S., Sorin H.. Influence of Geometry on the Position and the Intensity of Maximum Kinetic Energy in a Combustion Chamber. Diffusion in Solids and Liquids, 312-315, pp. 725-730,2011.

[6] Y.J. Jiao, H.M. Zhang, Y.Tian, et al. Multi-dimensional Simulation of Effect of Combustion Chamber Geometry on Emission in DI Diesel Engine. Chinese Internal Combustion Engine Engineering, 28(4), pp. 11-15, 2007 (in Chinese).

[7] J. Zhu, C. Huang, M. F. Yao. Numerical simulation on the effect of combustion chamber geometry on diesel engine combustion process. Chinese Internal Combustion Engine Engineering, 28(2), pp. 14-18, 2007 (in Chinese).

[8] Yadollahi B., Boroomand M.. The effect of combustion chamber geometry on injection and mixture preparation in a CNG direct injection SI engine. Fuel, 107, pp. 52-62, 2013.

[9] G.J. Zhou, Z.Y. Yan. Fluid Mechanics (the Second Edition). Beijing: Higher Education Press, 2000(in Chinese).

[10] S. Fu, Launder B. E., Leschziner M. A. Modeling strongly swirling recirculating jet flow with Reynolds-stress transport closures. In Sixth Symposium on Turbulent Shear Flows, Toulouse, France, 1987.

[11] Yakhot V., Orza S. A. g. Renormalization group analysis of turbulent: basic theory. J. Scient. Comput., 1, pp. 3-11,1986.

[12] Naber J. D., Reitz R. D.. Modeling engine spray-wall impingement. SAE Paper 880107, 1988.

[13] A. B. Liu, Daniel M., Reitz R. D.. Modeling the Effects of Drop Drag and Breakup on Fuel Sprays. SAE Paper 930072, 1993.

[14] Dukowiez J. K.. Quasi-steady droplet phase change in the presence of convection. New Mexieo:Los Alamos Scientific Laboratory,1979. 